\title{
The construction features of the deformation and force model of concrete and reinforced concrete resistance
}

\author{
Vasyl Romashko ${ }^{1 *}$, and Olena Romashko ${ }^{1}$ \\ ${ }^{1}$ Department of Architectural Designing Bases, Constructing and Graphics, National University of \\ Water Management and Nature Recourses Use, Soborna Street 11, Rivne 33000, Ukraine
}

\begin{abstract}
The main features of the deformation and force model of deformation of reinforced concrete elements and structures based on generalized diagrams of their state are considered in the article. Particular attention is focused on the basic methodological problems and shortcomings of modern "deformation" models. It is shown that in the most cases these problems can be solved by the generalized diagrams of reinforced concrete elements and structures real state. Thanks to these diagrams, the developed method: provides a single methodological approach to the calculation of reinforced concrete elements and structures normal sections for limit states; allows to reveal the internal static indeterminacy of heterogeneously deformable elements and structures in their ultimate limit state calculation; justifies the application of the basic and derived criteria of reinforced concrete elements and structures bearing capacity exhaustion; retains the essence of the physical processes of concrete and reinforced concrete structures deformation. The defining positions of the generalized (universal) methodology for calculating reinforced concrete elements and structures are stated.
\end{abstract}

\section{Introduction}

In general, the modern theory of concrete and reinforced concrete continues to move towards its further improvement. However, until now it has not developed an unambiguous attitude to its main object - reinforced concrete. Within the framework of the above theory, some researchers recognize the existence of two objects: reinforced concrete-material and reinforced concrete-construction. Others consider reinforced concrete only as a composite material, which has a non-linear relationship between stresses and deformations, creep, micro- and macroformation of cracks, etc. The existing situation, although it is explainable, cannot remain unchanged, since any truly scientific theory has an unique attitude towards the research object.

\section{Analysis of recent studies and publications}

\footnotetext{
${ }^{*}$ Corresponding author: romashkovasyl@gmail.com
} 
Already now, the basis for modern models of concrete and reinforced concrete resistance begins to be laid down for the sampling of calculation schemes and their representation as a set of elements of certain structural levels. In particular, Borovskikh A.V. distinguishes three hierarchical levels of research objects [1]: materials, elements of structures, structures and buildings. At the same time, Bondarenko V.M. [2] offers to classify objects of research for four structural levels: material, section (element), construction, constructive system of a building. However, one cannot agree with the identification of two structural levels: the section and the element. Therefore, it seems to be correct to classify the research objects according to the following five interrelated structural levels of hierarchical subordination. They are: material (a set of properties); cross-section (an aggregate or a combination of materials); an element (an aggregate or a combination of sections); structure (an aggregate or a combination of elements); constructive system of a building or construction (an aggregate or a combination of elements and structures).

Naturally, one of the main tasks in the modern concrete and reinforced concrete theory will continue to be the deep study and theoretical generalization of the specific properties of the above-mentioned composite material. And since it is always an integral part of the structure, then the theory of such material deformation should be only a part of a more general theory of concrete and reinforced concrete elements and structures deformation. Thus, a theory whose single-valued object will be an element or a structure will require clear, consistent and logical operations from researchers and will allow them to work purposefully on the generalized model of reinforced concrete elements and structures deformation.

In the existing deformation models $[3,4,5]$, the actual stress-strain state of reinforced concrete elements and structures is reproduced by transferring the deformation diagrams of materials to their sections. Such a method, according to many researchers $[6,7,8]$, is not very convincing and makes a number of reservations on their part. Therefore, in the proposed deformation and force model $[9,10]$, the entire process of concrete and reinforced concrete elements and structures deformation is reproduced using diagrams of their real state. In this case, there is no need for any transfer of the above diagrams to the crosssections of these elements, because under certain facts and boundary conditions they are transformed into each other.

\section{Issues not solved within the common problem}

Ensuring the full methodological unity of concrete and reinforced concrete elements and structures calculations on the ultimate states of the first and the second group (on strength, rigidity and crack resistance) has always been one of the most important problems in the concrete and reinforced concrete theory.

This problem could not be solved in principle in the framework of the force model using the "plastic hinge" with a rectangular stress diagram in the compressed concrete. After all, because of the different initial assumptions, the calculations of reinforced concrete elements and structures on the ultimate states of the first and the second group generally remained completely autonomous.

Special hopes in solving this problem were assigned to the so-called "deformation" model. However, despite some successes in its construction, it still did not fully solve the main problem. Moreover, within its framework, the accompanying tasks remain unresolved:

- in most cases, the internal static uncertainty of heterogeneously deforming elements is revealed through numerous iterations;

- there are no clear criteria for the exhaustion (loss) of the bearing strength of reinforcedconcrete elements and structures; 
- for today, for reinforced elements and structures, not only exact, but also approximate analytical solutions of integral dependences $M=f(1 / r)$ for the extreme criterion $d M / d(1 / r)=0$ are practically absent;

- in the calculations of the inhomogeneously deformed elements over the ultimate states of the second group, there are no recommendations or suggestions for disclosing their internal static indeterminacy, which leads to the inevitable use in calculations not only numerous iterative operations but also various kinds of empirical dependences.

\section{Purpose and objectives of research}

The research given are directed on working-out of the generalized universal calculation technique of reinforced concrete elements and structures on ultimate conditions which would:

- fully ensured the methodological unity of their implementation;

- was maximally devoid of empiricism;

- contributed to the disclosure of the internal static uncertainty of reinforced concrete elements and structures and to the significant reduction in iterative calculations;

- maximally preserved the physical essence of the deformation processes of reinforced concrete elements and structures;

- could be implemented by simple compact algorithms;

- preserved the methodological unity of precise and simplified calculation methods.

\section{Results and discussion}

To achieve this goal and cope with the above tasks, the entire process of reinforced concrete elements and structures deformation, and consequently the diagrams of their real state, in the deformation and force model is proposed to be reproduced using the rigidity function $D$. It is the latter that connects the main force $(M)$ and deformation $(1 / r)$ parameters of the stress strain-state of these elements and structures. In this case, experiments show that [11], up to the exhaustion of the bearing strength, the rigidity of the elements depends on these parameters nonlinearly. Therefore, thanks to the hypothesis of "non-linearity" of rigidity $[9,10]$, the pronounced dependence

$$
M /(1 / r)=A-B \cdot(1 / r) /\left(1 / r_{u}\right)-C \cdot M / M_{u},
$$

the state diagram connecting the forces in a reinforced concrete element $M$ with its curvature $1 / r$ takes the following form (Fig. 1)

$$
M=\frac{D_{0} \cdot 1 / r-M_{u} \cdot\left((1 / r) /\left(1 / r_{u}\right)\right)^{2}}{1+\left(D_{0} / M_{u}-2 /\left(1 / r_{u}\right)\right) \cdot(1 / r)}
$$

where $D_{0}$ - is the initial value of the full $\left(\sum E_{i} I_{i}\right)$ or reduced $\left(E_{c 0} I_{\text {red }, 0}\right)$ rigidity of the reinforced concrete element; $M_{u}$ - the bearing strength of a reinforced concrete rod (the maximum possible force in it when the limit state is reached); $1 / r_{u}-$ the ultimate value of the reinforced concrete element curvature when its bearing strength is exhausted.

The universality of the generalized diagram of the element state (2) is confirmed by the fact that under certain initial conditions it is transformed into a well-known diagram of the concrete state laid down in Eurocode 2 [3] 


$$
\sigma_{c}=f_{c k} \cdot \frac{E_{c 0} \cdot \varepsilon_{c} /\left(E_{c u} \cdot \varepsilon_{c u}\right)-\left(\varepsilon_{c} / \varepsilon_{c u}\right)^{2}}{1+\left(E_{c 0} / E_{c u}-2\right) \cdot\left(\varepsilon_{c} / \varepsilon_{c u}\right)}
$$

where $E_{c u}$ - the ultimate value of the secant modulus of concrete deformation, with axial compression $E_{c u}=E_{c f}=f_{c k} / \varepsilon_{c u} ; \varepsilon_{c u}-$ ultimate concrete deformation, with axial compression equal to critical $\varepsilon_{c u}=\varepsilon_{c 1}$.

The curvature of the reinforced concrete element, which is the root of the square equation (2), is determined by the formula

$$
\frac{1}{r}=\frac{1 / r_{u}}{2 M_{u}}\left[\left(1-\frac{M}{M_{u}}\right) \frac{D_{0}}{r_{u}}+2 M-\sqrt{\left(\left(1-\frac{M}{M_{u}}\right) \frac{D_{0}}{r_{u}}+2 M\right)^{2}-4 M \cdot M_{u}}\right]
$$

In the presence of cracks in the stretched zone of the reinforced concrete element, its curvature is corrected for expression $1 / r^{*}=(1 / r) \cdot \psi_{\rho}$ using a polynomial function of type

$$
\psi_{\rho}=1+\rho_{l} / \alpha_{s} \cdot\left(1-M / M_{u}\right) \cdot M / M_{u},
$$

where: $\alpha_{s}-$ the relative value of the armature elasticity modulus, $\alpha_{s}=E_{s} / 200000 ; \rho_{l}-$ the reinforcement percentage of the element cross-section by longitudinal rods, $\%$.

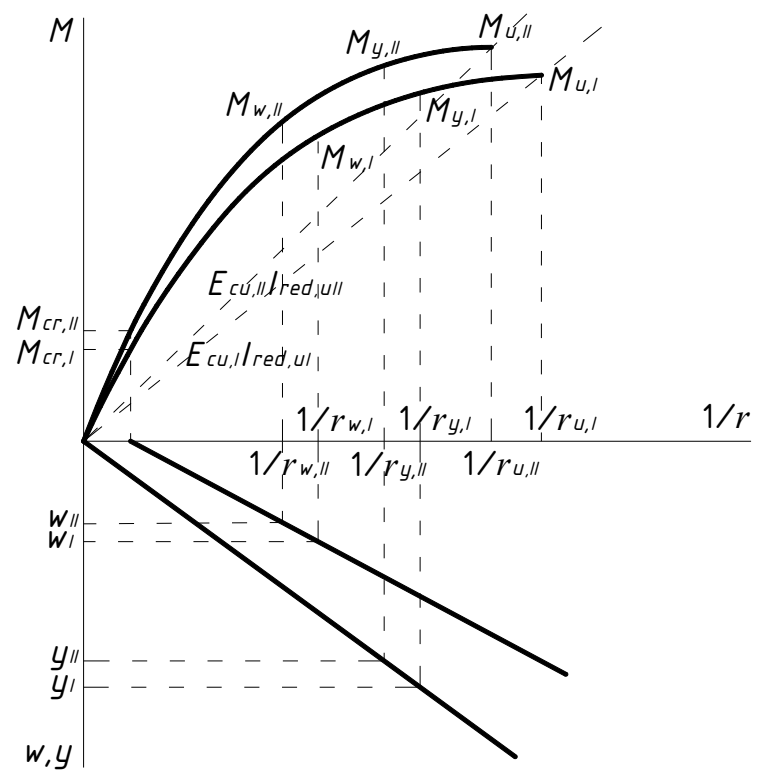

Fig. 1. Generalized characteristic and calculated state diagrams of the reinforced concrete elements and structures.

At the same time, using the hypothesis of flat sections, the current values of curvature are associated to the materials relative deformations in the most stressed cross-section or in the averaged cross-section of the most strained part of the element by the dependences

$$
1 / r=\left(\varepsilon_{c 2}+\varepsilon_{s}\right) / d \text { either } 1 / r=\left(\varepsilon_{c 2}+\varepsilon_{c 0}\right) / h_{c},
$$

where: $\varepsilon_{s}$ - deformations of the most stretched armature in the element cross-section; $\varepsilon_{c 2}$ 
and $\varepsilon_{c 0}$ - concrete deformation of the most and the least compressed fiber of cross-section; $d$ and $h_{c}$ - the working and total height of the reinforced concrete element cross-section.

Curvature, which depends on the basic strength and deformation characteristics of reinforced concrete elements, is one of the main parameters of the whole process of their deformation. Exactly the use of state diagrams, for which curvature is the defining parameter, provides a single methodological approach to calculating the reinforced concrete elements deflections regardless of the presence or absence of cracks in them.

Bearing strength exhaustion of reinforced concrete elements and structures in their normal cross-sections is characterized by a violation of one of the two well-known equilibrium equations $\sum N=0$ and $\sum M=0$. Usually, the second equation is more stringent, from which the defining condition of ultimate equilibrium follows $M_{E d} \leq M_{u}$, where $M_{E d}$ - the calculated value of the bending moment from the external load.

At all stages of concrete and reinforced concrete elements and structures deformation, the above equations have analytical and graphic solutions. Using these solutions dependence for the level of ultimate deformations of compressed concrete was obtained, using the notion of an extreme criterion of bearing strength $d M / d(1 / r)=0[10,12]$

$$
\begin{aligned}
& \eta_{\varepsilon u}=\varepsilon_{c u} / \varepsilon_{c 1}=1+5^{3} \cdot \alpha_{s} \cdot \frac{(k-1)}{(6-k)} \cdot \sum_{i=1}^{n} \rho_{l i} \cdot\left(\frac{x_{s i}}{x}\right)^{2}+\beta_{F} \times \\
& \times\left[\frac{\left(0,43-0,2\left(0,4-m_{h}\right)^{2}\right)\left(1-m_{h}^{3 / 2}\right)\left(1-m_{h} / k\right) \sqrt{(\ln k)^{\left(1-m_{h}^{3 / 2}\right)}}}{1+\left(\left(1 / 6-0,1 \cdot m_{h}^{2}\right)(k-2) \ln \left(6 / k-2\left(0,1-m_{h}\right)\right)\right)^{2}}+\right. \\
& \left.+\frac{\left(0,43-0,2\left(0,4-m_{b}\right)^{2}\right)\left(1-m_{b}^{3 / 2}\right)\left(1-m_{b} / k\right) \sqrt{(\ln k)^{\left(1-m_{b}^{3 / 2}\right)}}}{1+\left(\left(1 / 6-0,1 \cdot m_{b}^{2}\right)(k-2) \ln \left(6 / k-2\left(0,1-m_{b}\right)\right)\right)^{2}}\right],
\end{aligned}
$$

where $k$ - characteristic of compressed concrete deformability (elastoplasticity), $k=E_{c 0} \cdot \varepsilon_{c 1} / f_{c k} ; x_{s i}$ - the distance from the neutral line to the gravity center of compressed rods, the stresses in which, in the ultimate state, do not reach the yield point; $\rho_{l i}$ - the reinforcement coefficient of the element cross-section by the same rods, $\rho_{l i}=A_{s i} /\left(b_{c} \cdot h_{c}\right) ; \beta_{F}$ - the coefficient, depending on the type of stress-strain state of the element, is assumed to be equal to: for compressed elements -1.0 ; for bending $-0.81 ; m_{h}-$ the inhomogeneity parameter of deformation of compressed concrete along the side $h$, $m_{h}=\varepsilon_{c 0, h} / \varepsilon_{c 2} ; m_{b}-$ the inhomogeneity parameter of deformation of the compressed concrete along the side $b, m_{b}=\varepsilon_{c 0, b} / \varepsilon_{c 2}$ (Fig. 2).

Exactly the dependencies (4) to (6), together with (7), make it possible to avoid or substantially reduce the number of iterations, thus contributing to the disclosure of the internal static uncertainty of reinforced concrete elements and structures cross-sections.

If we resort to a semantic analysis of the diagrams of element state (2) and the diagrams of material state (3), then it should be said that they can be characteristic (normative) or calculated (Fig. 1). It is known that the first of them can be obtained only by using the actual properties of the raw materials: concrete and armature. Therefore, they should be used to evaluate the real stress-strain state of elements and structures by the results of experimental studies (full-scale tests). According to these diagrams, the basic (characteristic) parameters of the stress-strain state of reinforced concrete element can be 
determined: the bearing strength $M_{u, I I}=M_{0}$, the width of the cracks opening $w_{I I}=w_{0}$, and the deflection $y_{I I}=y_{0}$.
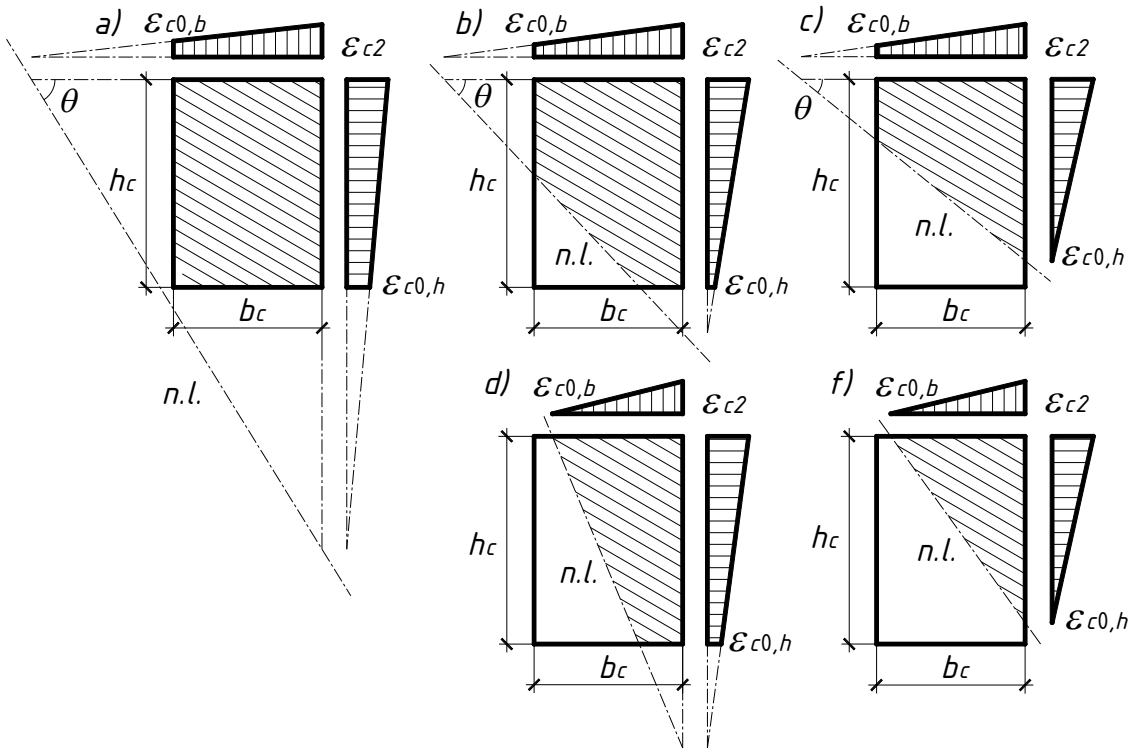

Fig.2. Possible cases of the position of the neutral line in the skew-deformed reinforced concrete element.

However, in the practice of reinforced concrete elements and structures designing, one should nevertheless rely on the calculated diagrams of their state. After all the real characteristics of the stress-strain state of reinforced concrete elements and structures $M_{u, I}=M_{u}, w_{I}=w_{k}$, and $y_{I}=y_{k}$ can differ significantly from the basic quantities $M_{0}$, $w_{0}$, and $y_{0}$, as a result of the possible variability of the strength and deformation properties due to the influence of various technological, structural and operational factors.

Consequently, the calculated state diagrams of reinforced concrete elements and structures as a whole provide possible weakening of concrete with a simultaneous increase in the parameters of its deformation. In such circumstances, there is no need to use various empirical coefficients that increase the basic parameters of reinforced concrete elements deformation $\left(w_{0}, y_{0}=f_{0}\right)$ to the level of calculated $\left(w_{k}, y_{k}=f_{k}\right.$ ).

Therefore, taking into account the generally recognized principles of the mechanics of deformed solid body (MDSB) and dependences (2) to (7), the calculation of the reinforced concrete element in the most stressed cross-section (or in the average cross-section of the most stressed area) with its nonlinear deformation is expedient to perform with the help of computer or even "manual" solution of the following closed system of MDSB equations:

- static ratios with the hypothesis of ultimate equilibrium $M=f\left(\varepsilon_{c}, \varepsilon_{c t}, \varepsilon_{s}\right)$, $N=f\left(\varepsilon_{c}, \varepsilon_{c t}, \varepsilon_{s}\right)$;

- geometric ratios $1 / r=f\left(\varepsilon_{c}, \varepsilon_{c t}, \varepsilon_{s}\right)$;

- physical ratios: the elements state $M=f(1 / r)$ with an extreme criterion of bearing strength $d M / d(1 / r)=0$; materials state $\sigma_{c}=f\left(\varepsilon_{c}\right), \sigma_{c t}=f\left(\varepsilon_{c t}\right)$, $\sigma_{s}=f\left(\varepsilon_{s}\right)$ with an extreme strength criteria $d \sigma_{c} / d \varepsilon_{c}=0, d \sigma_{c t} / d \varepsilon_{c t}=0$. 
For approbation of the above method, calculations of various reinforced concrete elements tested by domestic and foreign researchers were made. The deflections of the bent elements were calculated according to the well-known Simpson's formula using the curvature dependence (4), while the deflections of the compressed elements in the ultimate state were calculated mainly by the classical expression

$$
f_{\max }=s \cdot l^{2} \cdot\left(1 / r_{x}\right)_{\max },
$$

where $s$ - coefficient, depending on the loading and fastening of the element; $\left(1 / r_{x}\right)_{\max }-$ the average element curvature in the section with the greatest bending moment (the least stiffness).

The comparison results of the theoretical and experimental values of the investigated parameters, given in the table, indicate the legitimacy of developed methodology using in practical calculations.

Table 1. Comparison of theoretical and experimental parameters of reinforced concrete elements

\begin{tabular}{|c|c|c|c|c|c|c|}
\hline \multirow{3}{*}{$\begin{array}{l}\text { The experiments authors, the number } \\
\text { of samples }\end{array}$} & \multicolumn{6}{|c|}{$\begin{array}{l}\text { Deviation of the experimental data from the } \\
\text { calculated data obtained by the method }\end{array}$} \\
\hline & \multicolumn{3}{|c|}{ Eurocode 2 [3] } & \multicolumn{3}{|c|}{ Romashko V. } \\
\hline & $\Delta$ & $\sigma$ & $v, \%$ & $\Delta$ & $\sigma$ & $v, \%$ \\
\hline \multicolumn{7}{|c|}{$\begin{array}{l}\text { The bearing strength of eccentrically compressed, obliquely compressed and obliquely } \\
\text { bended reinforced concrete elements }\end{array}$} \\
\hline $\begin{array}{l}\text { Tal, K.E., Chistyakov, E.A. [13], } 68 \\
\text { samples }\end{array}$ & 1.023 & 0.0813 & 7.95 & 1.009 & 0.0763 & 7.56 \\
\hline Babich, S.V. [14], 15 samples & 1.05 & 0.1269 & 12.09 & 1.026 & 0.1146 & 11.17 \\
\hline Rizak, V.V. [15], 15 samples & 1.025 & 0.0979 & 9.55 & 1.016 & 0.0908 & 8.94 \\
\hline Babich, V.I. [16], 30 samples & 1.004 & 0.0426 & 4.24 & 1.014 & 0.043 & 4.24 \\
\hline Total, 128 samples & 1.022 & 0.0795 & 7.75 & 1.013 & 0.0747 & 7.37 \\
\hline \multicolumn{7}{|c|}{ Deflections of bent reinforced concrete elements } \\
\hline Burns, N.H., Siess C.P. [17], 18 samples & 1.022 & 0.1585 & 15.51 & 0.978 & 0.1104 & 11.29 \\
\hline $\begin{array}{l}\text { McCollister, H.M., Siess, C.P. [18], } 18 \\
\text { samples }\end{array}$ & 0.978 & 0.065 & 6.64 & 0.997 & 0.063 & 6.32 \\
\hline Ernst G.C. [19], 20 samples & 1.009 & 0.1881 & 18.64 & 1.018 & 0.1421 & 13.96 \\
\hline $\begin{array}{l}\text { Rashid, M.A., Mansur, M.A. [20], } 13 \\
\text { samples }\end{array}$ & 1.137 & 0.2489 & 21.89 & 1.046 & 0.177 & 16.92 \\
\hline Total, 69 samples (234 experiments) & 1.051 & 0.1807 & 16.94 & $\mathbf{1 . 0 1 5}$ & 0.133 & 13.03 \\
\hline
\end{tabular}

Notes: $\Delta=M_{t h} / M_{e x}\left(f_{t h} / f_{e x}\right)$ and $\sigma$ - arithmetic mean and standard deviations between experimental and calculated values, $v$ - variance coefficient of deviations

\section{Conclusion}

Thus, due to the generalized actual state diagram of concrete and reinforced concrete elements and structures $M-1 / r$, the proposed deformation-force model:

- provides a unified methodological approach to the calculation of reinforced concrete elements on the ultimate states of the first and the second group;

- allows to disclose the internal static indeterminacy of heterogeneously deformed elements in their calculations on ultimate states;

- justifies the use of the basic $\left(M_{E d} \leq M_{u}\right)$ and derived $(d M / d(1 / r)=0)$ criteria for the bearing strength exhaustion of reinforced concrete elements and constructions; 
- does not require the use of complex software and allows to perform most calculations even "manually";

- to a certain extent, localizes the influence of empirical parameters on the methodology for calculating reinforced concrete elements and structures.

\section{References}

1. V.M. Bondarenko, V.I. Kolchunov, Calculated models of power resistance of reinforced concrete (St. Petersburg, Moscow, ASV, 2004)

2. A.V. Borovskikh, Calculations of reinforced concrete structures on limiting states and limit equilibrium (Moscow, DIA Publishing House, 2004)

3. EN 1992-1-1, Eurocode 2: Design of Concrete Structures (Brussels, CEN, 2004)

4. SNB 5.03.01-02, Concrete and reinforced concrete structures (Minsk, Stroytechnorm, 2003)

5. DSTU B V.2.6-156: 2010, Construction of buildings and structures (Kiev, Minregionbud Ukraine, 2011)

6. N.I. Karpenko, T.A. Mukhamediev, A.N. Petrov, Stress-strain state of concrete and reinforced concrete structures (Sci. Works), 1, 7-25 (Moscow, NIIGB, 1986)

7. I.A. Uzun, IZV VUZ CONSTR ARCHIT, 11, 7-12 (1991)

8. V.S. Dorofeev, V.Yu. Bardanov, Calculation of bent elements taking into account the complete diagram of concrete deformation (Odessa, OGASA, 2003)

9. V.M. Romashko, INT SCI J, 3, 84-86 (2016)

10. V.M. Romashko, The deformation and power model of concrete and reinforced concrete resistance (Rivne, O. Zen, 2016)

11. B.Ya. Ryskind, G.I. Shornikova, Reinforced Concrete Structures: Sci. Works, VI, $42-$ 71, (Chelyabinsk, UralNIIstromproekt, 1972)

12. V.M. Romashko, CONSTR OPT ENERG POTENT, 2(16), 75-83 (2015)

13. K.E. Tal, E.A. Chistyakov, Calculation of reinforced concrete structures. Experimental and theoretical studies to improve the calculation: works NIIGB, 23, 127-195 (1961)

14. S.V. Babich, Work and load-bearing capacity of compressed reinforced concrete elements with different eccentricity at the ends (Thesis of Doct. PhD Tech. Sciences, Rivne, 1998)

15. V.V. Rizak, Work and load-bearing capacity of compressed-bent ferro-concrete elements under short-term loading (Thesis of Doct. PhD Tech. Sciences, Rivne, 2000)

16. V.I. Babich, Experimental-theoretical studies of the operation of flexible reinforced concrete elements of rectangular cross-section on oblique eccentric compression (Thesis of Doct. PhD Tech. Sciences, Lviv, 1972)

17. N.H. Burns, C.P. Siess, Load-deformation characteristics of beam-column connections in reinforced concrete: A report of a research project (Urbana, University of Illinois, 1962)

18. H.M. McCollister, C.P. Siess, N.M. Newmark, Load-deformation characteristics of simulated beam-column connections in reinforced concrete. A technical report of a research project (Urbana, University of Illinois, 1954)

19. G.C. Ernst, ACI J, 28 (12), 1119-1144 (1957)

20. M.A. Rashid, M. A. Mansur, ACI STRUCT J, 102 (3), 462- 471 (2005) 